\title{
Um desafio para a saúde pública brasileira: o controle do dengue
}

\author{
Dengue control: a challenge for the public \\ health system in Brazil
}

Maria Lucia F. Penna 1

\footnotetext{
1 Departamento de Endemias Samuel Pessoa, Escola Nacional de Saúde Pública, Fundação Oswaldo Cruz. Rua Leopoldo Bulhões 1480, Rio de Janeiro, $R J$ 21041-210, Brasil. mlpenna@ensp.fiocruz.br
}

\begin{abstract}
This article presents a critical analysis of the traditional strategy used to control Aedes aegypti using "health surveillance patrols", with periodic visits to all urban buildings. The strategy is not viable and/or is administratively unfeasible at present, since it has been proposed since the 1980s but has not been implemented. Brazilian health reform prioritized the expansion of coverage for basic health services, and not measures to control specific diseases. A. aegypti, which was reintroduced and began the reoccupation of its old habitat in 1976, is currently in a process of re-infesting the country until reaching equilibrium. This public health problem relates to the urban environment and is thus a problem that affects everyone, both the population and government, and not merely the health sector. The article highlights the need for joint action in sanitation and the environment. The population's role should also be reshaped as effective and permanent, separating the rights and duties of government and the population, i.e., making a clear distinction between the public and private domains. The danger of resurgence of yellow fever should be considered when establishing a new, feasible strategy for dealing with the dengue problem.
\end{abstract}

Key words Dengue; Yellow Fever; Aedes; Vector Control; Mosquito Control

Resumo Este artigo problematiza a estratégia tradicional de controle do Aedes aegypti por meio do trabalho de guardas sanitários, com visitas periódicas a todas as edificações urbanas. Ela não é viável elou não tem factibilidade administrativa atualmente, já que vem sendo proposta desde a década de 80 e não é implementada. A reforma sanitária brasileira priorizou a ampliação da cobertura dos serviços básicos de saúde e não as ações de controle de doenças específicas. O A. aegypti reintroduzido para iniciar a reocupação de seu antigo habitat em 1976, está atualmente em um processo de reocupação do país até atingir seu equilíbrio Isto como problema de saúde coletiva, diz respeito ao meio ambiente urbano, portanto um problema de todos, população e poder público, não apenas da área de saúde. A necessidade da atuação conjunta da área de saneamento e meio ambiente neste caso é ressaltada. Deve-se também repensar a contribuição da população como efetiva e permanente, separando obrigações e direitos do poder público e da população, separando o público do privado. O perigo do reaparecimento da febre amarela deve ser considerado no estabelecimento de uma nova estratégia factível e viável para lidar com o problema do dengue.

Palavras-chave Dengue; Febre Amarela; Aedes; Controle de Vetores; Controle de Mosquitos 
O isolamento no início de 2001 do vírus dengue 3 no Rio de Janeiro, indicava a ocorrência de uma epidemia no verão 2001/2002 com intensidade dependente da densidade vetorial (quantidade de mosquito por habitante). Do mesmo modo que a ocorrência da epidemia pôde ser prevista, com meses de antecedência por qualquer epidemiologista familiarizado com dinâmica de transmissão, seu fim, no Rio de Janeiro, no mês de maio de 2002 por esgotamento de susceptíveis e redução sazonal da densidade vetorial, independente de qualquer medida de controle, era previsível. A experiência com as epidemias ocorridas quando da introdução dos vírus tipo 1 e tipo 2 apóia esta afirmativa.

Esta epidemia não será a última. O vírus dengue 4 já circula no continente e provocará epidemia se o controle vetorial permanecer ineficiente.

Quando o problema é controle do dengue, aparentemente já conhecemos a resposta técnica: controle do Aedes aegypti por meio do trabalho de guardas sanitários, que devem periodicamente visitar todas as edificações urbanas. A força ideológica dessa estratégia tradicional se expressa na abordagem dos meios de comunicação ao cobrir o controle do dengue, onde este ponto jamais é problematizado. Chamados a repensar a estratégia, alguns especialistas de prestígio afirmam que não se trata de propor mudanças, já que a estratégia tradicional jamais foi implementada desde o reaparecimento da doença no país na década de 80 . No entanto, se encararmos a questão não simplesmente como um problema entomológico, virológico e médico, mas como um problema de saúde coletiva, devemos nos perguntar porque essa estratégia, defendida tão enfaticamente como a única verdade, com o apoio da figura mítica de Oswaldo Cruz, o patrono da saúde pública brasileira, não é implementada. Claramente ela não é viável e/ou não tem factibilidade administrativa atualmente.

A reforma sanitária brasileira em um primeiro momento priorizou a ampliação da cobertura dos serviços básicos de saúde, de modo a atender o princípio da universalidade de acesso à saúde, e não ações de controle de doenças específicas, principalmente aquelas ações que não tivessem efeito sinérgico para a atenção básica. O desenvolvimento do SUS envolveu a construção de consensos em torno de modelos de financiamento, modelo gerencial, de organização dos serviços de saúde e de atenção. A discussão sobre o controle vetorial foi sempre completamente periférica porque essa atividade não se realiza na rede de atenção à saúde, arcabouço principal do SUS. A situação do dengue reflete, portanto, a decisão política de não priorizar o controle vetorial no país no primeiro momento da construção do SUS. O custo deste controle realizado por meio da estratégia tradicional é muito alto, com um custo benefício baixo comparado à expansão da cobertura das ações básicas de saúde.

A descentralização, outro dos princípios do SUS, tem como objetivo o aumento da eficiência e efetividade das ações desenvolvidas, uma vez que estas seriam adequadas às diferentes realidades locais. A principal crítica à atuação verticalizada da antiga Superintendência de Campanhas de Saúde Pública (SUCAM) era justamente a tomada de decisões técnicas em nível nacional com a execução acrítica de atividades por todo o país. No entanto, o que se vê no controle do dengue é a municipalização de uma execução acrítica, cujas normas continuam vindo do nível federal. No último trimestre de 2002, a Fundação Nacional de Saúde (FUNASA), anunciou um grande recurso financeiro para o combate à dengue no Estado do Rio de Janeiro, e em uma primeira proposta na Comissão Intergestora Bipartide (CIB), apresentou a proposta de repasse de $10 \%$ do valor anunciado ao estado e municípios para a contratação de pessoal, e o restante dos recursos seriam utilizados na compra, pela própria FUNASA, de veículos, equipamentos, tampas de caixa d'água, etc., que seriam repassados aos municípios, segundo demanda justificada a ser feita diretamente em nível federal. O que se vê, portanto, é a transposição de antigas práticas de organização verticalizada para os municípios executarem descentralizadamente. Questões técnicas como o conhecimento entomológico e o manejo seguro de inseticidas foram desprezadas. Há, por exemplo, relatos de surtos de pneumonite por uso de diluente inadequado para a borrifação ultra baixo volume de inseticida (fumacê). O que se vê hoje é também a utilização de antigas desculpas. A culpa é da população, que na verdade não foi alertada nem adequadamente instruída sobre o controle de criadouros oportunamente.

O contraste entre o que assistimos hoje e o modo eficiente com que a Região Sudeste enfrentou a epidemia de cólera no início da década de 90 vale a pena ser examinado. Diante da hipótese da introdução da cólera na região, a população foi instruída sobre a lavagem de verduras e frutas, foi recomendada a limpeza das caixas d'água de residências e condomínios, e as companhias de água e esgoto intensificaram a vigilância do sistema para detecção de falhas, com a avaliação da qualidade da água não só 
na entrada das residências como nas torneiras por amostragem. Os órgãos responsáveis pelo meio ambiente monitoraram a contaminação ambiental de água superficial e subterrânea, e auxiliaram na avaliação da qualidade e cloração da água para consumo humano. Vários projetos de despoluição de bacias hidrográficas e baías foram iniciados. Vale lembrar que o projeto de despoluição da Baía da Guanabara tem como principal componente o saneamento da Baixada Fluminense.

A relevância da atuação conjunta da área de saneamento e meio ambiente neste caso deve ser ressaltada e devemos lembrar que, embora o saneamento seja uma responsabilidade municipal, sendo o município o poder concessionário, em grande parte do país são companhias estaduais de água e esgoto que executam, sob concessão, essa tarefa. Assim, a competência e responsabilidade municipais não são incompatíveis com uma organização estadual das atividades, com incorporação adequada de tecnologia.

No caso do dengue, as informações repassadas à população, além de tardias foram incompletas. O uso da creolina em ralos, sem dúvida factível e barata, é lembrado pelos mais velhos, herança da campanha bem sucedida de erradicação do Aedes. A informação de que a larva nunca se desenvolve até a forma alada em menos de 7 dias, ( 11 a 18 dias a $26^{\circ} \mathrm{C}$ ) que permitiria a vigilância e eliminação de possíveis criadouros com periodicidade menor, não foi passada à população. O comportamento doméstico do Aedes, em contraste com outros mosquitos semidomésticos ou silvestres, também não foi devidamente esclarecido. A população da cidade do Rio de Janeiro manifesta constantemente preocupação pela proximidade de florestas. Dizer que o dengue se pega em casa não basta. A malária transmitida pelo Anopheles darlingi também se pega em casa, embora seus criadouros sejam naturais, em contraste com os criadouros fabricados pelo homem do A. aegypti.

$\mathrm{O}$ A. aegypti não é nativo das Américas, tendo sido introduzido no Brasil a partir da África, provavelmente no início do século XIX. Tendo encontrado um meio ambiente adequado à sua sobrevivência e reprodução, ocupou o país no sentido de que progressivamente se expandiu geograficamente e aumentou a sua população. Ele foi erradicado do país em 1957, reintroduzido em 1967 e novamente eliminado em 1973, e finalmente reintroduzido para iniciar a reocupação de seu antigo habitat em 1976. Observe-se que desde as primeiras atividades de controle do mosquito no país no início do século
XX, e sua erradicação, passaram mais de cinqüenta anos. Sem intervenção espera-se que no atual processo de reocupação o A. aegypti se expanda geograficamente e aumente sua densidade até um ponto de equilíbrio determinado pelo meio ambiente. A distribuição dos casos de dengue no tempo e espaço deste 1985, quando foi introduzido no Rio de Janeiro, reflete este processo de reocupação do A. aegypti, ainda em curso. Note-se que 26 anos é um período curto para este processo. Estamos portanto diante de uma reocupação que ainda não atingiu o equilíbrio e não de focos limitados decorrentes de reintrodução recente.

A erradicação entre 1967 e 1973, se deu pela utilização do método perifocal que constituía na aplicação de inseticidas de efeito residual de seis meses em paredes externas e internas de todos os depósitos domiciliares com ou sem água, assim como nas paredes próximas até $1 \mathrm{~m}$ de distância dos eventuais criadouros. Tal método torna os criadouros preferenciais do mosquito armadilhas mortais para fêmeas, além de eliminar as larvas provenientes dos ovos aderidos às paredes dos recipientes quando estes são novamente preenchidos por água. Existiu portanto uma estratégia baseada no conhecimento sobre a ecologia do mosquito, e na sua dinâmica de população, ou seja, em que etapa do processo de erradicação a situação se encontrava. Essa prática era realizada por guardas sanitários.

A organização atual do espaço dos grandes centros urbanos e a situação da população de mosquitos no país levou à conclusão de que a erradicação do A. aegypti de forma semelhante não é mais viável. O Ministério da Saúde (MS) passou então a recomendar o controle e não mais a erradicação. Controle significa a redução permanente da densidade vetorial, o que só será possível com a eliminação definitiva de criadouros que respondam por grande parte da reprodução do vetor. Entretanto, nenhum trabalho sistemático foi, ou é, realizado para conhecer quais os principais criadouros existentes hoje. A utilização de larvicidas ou adulticidas por agentes de saúde não resultará em controle vetorial, mas apenas em redução temporária de sua densidade. Larvicidas são instrumentos centrais para erradicação do vetor, não para seu controle. Centrar o controle no trabalho de guardas sanitários apenas, como no início do século XX, tempo de Oswaldo Cruz, não tem sido, nem será, efetivo.

O problema diz respeito ao meio ambiente urbano, um problema de todos, população e autoridades, não apenas da área de saúde. É preciso envolver o setor de urbanismo das pre- 
feituras de forma a evitar edificações com arquitetura que permitam possíveis criadouros, alertar e fiscalizar construções que são grandes geradores de criadouros, com seus entulhos e recipientes, exigir boa drenagem de superfícies impermeabilizadas como, por exemplo, lages. Acredito também que uma cooperação efetiva com o setor do meio ambiente é essencial. Afinal estamos tratando da ecologia de vetores e reservatórios e do uso de inseticidas. As empresas que prestam serviços de controle de insetos e roedores são credenciadas por organismos estaduais de meio ambiente, como a Fundação Estadual de Engenharia do Meio Ambiente (FEEMA), no Estado do Rio de Janeiro. Tal credenciamento diz respeito apenas à segurança no manejo de inseticidas ou também à sua eficiência para vetores específicos? É preciso ainda ter a consciência de que a coleta de lixo e a distribuição de água potável estão diretamente relacionadas ao controle do A. aegypti, pela possibilidade do lixo e a água armazenada para consumo no caso de provisão intermitente pela rede virarem criadouros do mosquito.

A população já mostrou que responde bem a propostas de controle do dengue. Resta pensar na sua contribuição como efetiva e permanente. Enquanto se insiste na importância de pneus, nada é dito sobre os macro criadouros, como por exemplo, grandes poças em lages de empresas, que podem ser localizadas pela população e assim ter sua localização informada às equipes de guardas. Os macro criadouros são os que alimentam os pequenos criadouros, como ralos e pratos de plantas. A variação da densidade vetorial mais correlacionada com as chuvas do que com a temperatura reflete a importância maior de criadouros ao ar livre do que dos existentes dentro das casas, aí incluída a água para consumo humano.

Acredito que a população deve receber a melhor e mais recente informação possível, ter meios de comunicação com os responsáveis pelo controle vetorial e acesso a todos os meios disponíveis para o controle vetorial doméstico, de sua responsabilidade. É hora de separar o espaço público do privado no controle do dengue, assim como empresas de cidadãos. Da mesma forma que é de responsabilidade de uma empresa a não emissão de poluentes na atmosfera, também o é não possuir um macro criadouro de A. aegypti. Em termos práticos, temos de distinguir o que deve ser normalizado e fiscalizado do que deve ser executado diretamente pelo poder público, e do que fazer para viabilizar as ações privadas de controle no ambiente doméstico. Cabe ao poder público a coleta adequada de lixo, o suprimento contí- nuo de água, o cuidado com o espaço público, como por exemplo, não deixar que lagos em praças se tornem grandes criadouros ou não manter caçambas para coleta de lixo sem tampa, a criação de regras e fiscalização de atividades comerciais, industriais e da construção civil. Cabe ao poder público informar à população sobre riscos e medidas a serem tomadas no espaço doméstico com base na realidade de organização do espaço domiciliar e peridomiciliar. Por exemplo, enquanto muitas casas possuem tanques ao ar livre que se tornam criadouros no verão, acredito que em poucos quintais encontram-se pneus velhos armazenados.

Cabe também informar sobre a efetividade de produtos e serviços que vêm sendo vendidos para o combate à dengue. Uma grande rede de lojas, nos jornais de Domingo, dia 3 de novembro de 2002, anunciou para o combate à dengue sete diferentes produtos, incluindo pulverizadores de inseticidas. Que tipo de inseticida é disponível para uso doméstico que possa ser utilizado em pulverizadores? Empresas de paisagismo anunciam produto e serviço para o combate à dengue. Durante a epidemia do ultimo verão, vários condomínios contrataram empresas para combater a forma alada.

$O$ atual governo do Estado do Rio de Janeiro, consultou a FUNASA sobre a possibilidade de distribuição do biolarvicida BTI (Bacillus turingiensis variedade israelense) em formulação líquida à população nas escolas e unidades de saúde, encontrando oposição a esta medida. O BTI, além de utilizado na água de consumo humano por recomendação do próprio MS, é disponível para a compra nos Estados Unidos para uso doméstico. Seu uso é incentivado pelas autoridades sanitárias de Nova York, preocupadas com o controle de mosquitos transmissores de encefalite. Trata-se de um produto inofensivo para mamíferos e sem registro de desenvolvimento de resistência em campo. Sua distribuição à população carente e venda em geral pode, sem dúvida, implementar de modo importante o controle intra domiciliar do mosquito. Trata-se de um produto cujo efeito residual é de apenas 15 dias, sendo portanto irracional que venha sendo depositado em criadouros não elimináveis domésticos - ralos, tanques, etc. - por guardas sanitários quando possível (norma do MS, de 3 em 3 meses) e não a cada quinzena pelos moradores. Colocar essa atribuição para guardas sanitários é, em minha opinião, comparável a, durante o risco de cólera, ter guardas sanitários para lavar as saladas cruas das refeições domésticas, quando ao invés disso, o hipoclorito foi distribuído à população de baixa renda sob maior risco, pelas uni- 
dades básicas de saúde com instruções sobre seu uso.

A presença de altas densidades de A. aegyp$t i$ alerta sobre o perigo do reaparecimento da febre amarela urbana como já foi intensamente divulgado. A última e recente epizootia de febre amarela atingiu o sul de Minas Gerais, com casos humanos. Isso aponta que as ações de conservação ambiental, com a política de corredores ecológicos, integraram ecossistemas que se encontravam isolados - florestas da Mata Atlântica, com o Serrado e a Floresta Amazônica. Precisamos lembrar que no Rio de Janeiro existe um contato importante entre o meio ambiente urbano e a Mata Atlântica. Atualmente, sabemos das epizootias de febre amarela pelo aparecimento de casos humanos, embora esporádicos. Sistemas de vigilância da doença entre macacos nas áreas de preservação ambiental são sem dúvida uma alternativa, aparentemente mais cara para os cofres públicos, mas certamente mais civilizada para o acompanhamento deste risco.
Diante de uma epidemia, o controle vetorial entra na pauta política. Mas se a epidemia não tivesse ocorrido? Haveria bônus político? Como outros desastres naturais, as epidemias precisam ser tangíveis para que a população valorize as intervenções. Na peça de teatro $O$ Inimigo do Povo de Ibsen, um médico denuncia a contaminação de fontes de água em uma estância hidro-mineral. No nosso caso não houve "o inimigo do povo", pois o tamanho da epidemia a tornou visível por qualquer um, dispensando diagnósticos técnicos. A questão da peça era encobrir ou não um risco à saúde. A nossa questão é propor e implementar uma estratégia de controle da febre amarela e do dengue factível e viável, e para isso é necessário que a proposta e seus riscos e custos sejam amplamente discutidos, para a criação de consenso no meio técnico e para que o poder público e a sociedade brasileira os assumam como uma escolha. No aspecto técnico, podemos começar discutindo a conveniência de ampliar a vacinação antiamarílica enquanto continuarmos a conviver com o A. aegypti em nossas áreas urbanas.

Recebido em 26 de novembro de 2002

Aprovado em 29 de novembro de 2002 